\title{
Ring-opening Polymerization of Oxepane
}

\author{
Takeo Saegusa, Toshiaki Shiota, Shu-ichi Matsumoto, and Hiroyasu Fuji \\ Department of Synthetic Chemistry, Faculty of Engineering, \\ Kyoto University, Kyoto, Japan.
}

(Received June 4, 1971)

\begin{abstract}
A method for the preparation of a seven-membered cyclic ether of oxepane of high purity was established. The polymerization of oxepane was successfully performed by cationic initiators such as $\mathrm{Et}_{3} \mathrm{OBF}_{4}, \mathrm{Et}_{3} \mathrm{OSbCl}_{6}$, and $\mathrm{SbCl}_{5}$-epichlorohydrin. The product polymer (mol wt 2500$)$ was a crystalline solid $\left(2 \theta=19.6^{\circ}\right.$ and $24.1^{\circ}, \mathrm{mp}$ $\left.56-58^{\circ} \mathrm{C}\right)$. The equilibrium monomer concentration $[\mathrm{M}]_{\mathrm{e}}$ was determined from the equilibrated systems both of polymerization and depolymerization, $[\mathrm{M}]_{\mathrm{e}}=8 \times 10^{-2} \mathrm{~mol} / \mathrm{l}$ at $30^{\circ} \mathrm{C}$ and $6 \times 10^{-2} \mathrm{~mol} / l$ at $10^{\circ} \mathrm{C}$. On the basis of $[\mathrm{M}]_{\mathrm{e}}$, the strain energy of the oxepane monomer was discussed.

KEY WORDS Oxepane / Ring-opening Polymerization / Cationic Initiator / Polyoxepane / Equilibrium Monomer Concentration / Strain Energy /
\end{abstract}

In ring-opening polymerization, the relation between the ring-sizes and reactivities of a series of cyclic monomers is one of the most fundamental problems. As to cyclic ethers, the polymerizations of three-, four-, and five membered cyclic ethers have been widely studied. The reaction rates of the cationic polymerizations of four- ${ }^{1}$ and five membered ${ }^{3-5}$ cyclic ethers constitute a part of the basis for the quantitative consideration of reactivity. The present paper is concerned with seven-membered cyclic ether of oxepane (oxacycloheptane). The polymerization of oxepane has been described very briefly in a patent. In the present study, the procedure of the preparation and purification of oxepane is established, and the features of its polymerization-depolymerization equilibrium, as well as the basic characterization of polymer are disclosed.

\section{RESULTS AND DISCUSSION}

\section{Preparation and Purification of Oxepane}

Several methods have been reported for the preparation of oxepane. In the dehydrations of hexamethyleneglycol by sulfuric acid and by acidic metal oxide, ${ }^{7-9}$ the product mixture was shown by GLPC analysis to contain several byproducts such as 2-methyltetrahydropyran and 2-ethyltetrahydrofuran which could not be sepa- rated from oxepane by fractional distillation. The oxepane preparation by the treatment of 6bromohexyl methyl ether with ferric chloride ${ }^{10}$ also resulted in the formation of by-products which were not separable from oxepane by fractional distillation. The production of inseparable by-products is due to the unavoidable side reaction of the isomerization of the carbonium ion intermediate, which is a perplexing problem in these procedures. The ring-closure of a bromohydrin by $\mathrm{KOH}^{11}$ proved to be satisfactory for the preparation of pure oxepane. The GLPC analysis of the ring-closure mixture from 6bromo-1-hexanol showed only one by-product of 5-hexen-1-ol, which was made readily separable from oxepane by treatment with bromine water. Repeated fractional distillation on sodium metal gave pure oxepane, whose purity was shown by GLPC analysis to be over $99.9 \%$.

\section{Polymerization of Oxepane}

Oxepane was polymerized by various cationic initiators (Table I). Except for $\mathbf{S b C l}_{5}$, Lewis acid alone did not induce the oxepane polymerization. Similar behavior of Lewis acids was observed also in the polymerization of tetrahydrofuran (THF). ${ }^{12}$ Without any initiating additive, $\mathrm{SbCl}_{5}$ alone polymerizes both $\mathrm{THF}^{12}$ and oxepane.

Addition of a small amount of epichlorohydrin 
(ECH) to the Lewis acid catalyst was quite effective. The effect of $\mathrm{ECH}$ is explained in terms of the promoter. ${ }^{4,14}$ Besides ECH, $\beta$-propiolactone and oxetane were also effective as promoter (Table II). The $\mathrm{AlEt}_{3}-\mathrm{H}_{2} \mathrm{O}$ system did not cause oxepane polymerization even in the presence of the $\mathrm{ECH}$ promoter. Trialkyloxonium salts such as $\mathrm{Et}_{3} \mathrm{OBF}_{4}$ and $\mathrm{Et}_{3} \mathrm{OSbCl}_{6}$ were very efficient initiators as in the polymerizations of oxetane and THF.

The polymerization rate of oxepane was found to be very slow. In the cases of polymerizations with the above oxonium salt initiators, an almost

Table I. Polymerization of oxepane ${ }^{a}$

\begin{tabular}{|c|c|c|}
\hline Catalyst & $\begin{array}{c}\text { Time, } \\
\text { day }\end{array}$ & $\begin{array}{c}\text { Conversion, } \\
\%\end{array}$ \\
\hline \multicolumn{3}{|c|}{ Polymerization at $30^{\circ} \mathrm{C}$} \\
\hline $\mathrm{Et}_{3} \mathrm{OBF}_{4}$ & 8.5 & 83 \\
\hline $\mathrm{Et}_{3} \mathrm{OSbCl}_{6} \mathrm{~b}$ & 38 & 97 \\
\hline $\mathrm{BF}_{3} \mathrm{THF}$ & 8.5 & 0 \\
\hline $\mathrm{BF}_{3} \mathrm{THF} / \mathrm{ECH}^{\mathrm{c}}$ & 8.5 & 41 \\
\hline $\mathrm{AlEt}_{3}-\mathrm{H}_{2} \mathrm{O}$ & 8.5 & 0 \\
\hline $\mathrm{AlEt}_{3}-\mathrm{H}_{2} \mathrm{O} / \mathrm{ECH}$ & 8.5 & trace \\
\hline $\mathrm{SnCl}_{4}$ & 8.5 & 0 \\
\hline $\mathrm{SnCl}_{4} / \mathrm{ECH}$ & 8.5 & 26 \\
\hline $\mathrm{SbCl}_{5}$ & 8.5 & 30 \\
\hline $\mathrm{SbCl}_{5} / \mathrm{ECH}$ & 8.5 & 88 \\
\hline \multicolumn{3}{|c|}{ Polymerization at $10^{\circ} \mathrm{C}$} \\
\hline $\mathrm{Et}_{3} \mathrm{OBF}_{4}$ & 65 & $94^{\mathrm{d}}$ \\
\hline $\mathrm{Et}_{3} \mathrm{OSbCl}_{6}$ & 38 & 98 \\
\hline $\mathrm{BF}_{3} \mathrm{THF} / \mathrm{ECH}$ & 14 & 53 \\
\hline $\mathrm{AlEt}_{3}-\mathrm{H}_{2} \mathrm{O} / \mathrm{ECH}$ & 26 & trace \\
\hline
\end{tabular}

a Solution polymerization in $\mathrm{CH}_{2} \mathrm{Cl}_{2}$. Oxepane, $8.62 \mathrm{mmol} ;[\mathrm{M}]_{0}, 4.31 \mathrm{~mol} / l ;[\mathrm{Cat}]_{0}, 2 \mathrm{~mol} \%$.

b $[\mathrm{M}]_{0}, 3.45 \mathrm{~mol} / \mathrm{l}$.

c ECH: epichlorohydrin (as a promoter), $2 \mathrm{~mol} \%$.

d The vpo mol wt 2500.

Table II. Polymerization of oxepane (Effect of promoter) ${ }^{\mathrm{a}}$

\begin{tabular}{lcc}
\hline Promoter & $\begin{array}{c}\text { Time, } \\
\text { day }\end{array}$ & $\begin{array}{c}\text { Conversion, } \\
\%\end{array}$ \\
\hline No promoter & 8.5 & 0 \\
Epichlorohydrin & 38 & 41 \\
$\beta$-Propiolactone & 38 & 14 \\
Oxetane & 38 & 18 \\
\hline
\end{tabular}

a Solution polymerization in $\mathrm{CH}_{2} \mathrm{Cl}_{2}$ at $30^{\circ} \mathrm{C}$. Oxepane, $8.62 \mathrm{mmol} ;[\mathrm{M}]_{0}, 3.45 \mathrm{~mol} / l . \mathrm{BF}_{3} \mathrm{THF}$ and promoter were each $2 \mathrm{~mol} \%$. quantitative conversion percent was attained only after about one month both at 10 and $30^{\circ} \mathrm{C}$. The extent of polymerization at the same reaction time differed according to the nature of the intiator. It seems probable that the conversion percent is controlled mainly by the stability of the propagating species. As will be reported in a separate paper, the decrease rate of the concentration of the propagating species is generally high in oxepane polymerization. Further, it is relevantly mentioned that a big change of the termination rate according to the nature of the initiator has been observed in THF polymerization. $^{3}$

\section{Polymer Characterization}

The oxepane polymer is a crystalline solid. It is soluble in chloroform, 1,2-dichloroethane, THF, ether, benzene, cyclohexane, and petroleum ether, and insoluble in water, methanol, acetone, and dimethyl sulfoxide. The X-ray diffraction pattern shows two crystalline peaks at $2 \theta=19.6^{\circ}$ and $24.1^{\circ}$. A polymer sample having a molecular weight of 2500 melted at $56-58^{\circ} \mathrm{C}$. The IR spectrum has an $\nu_{\mathrm{C}-\mathrm{O}-\mathrm{C}}$ absorption at 1120 $\mathrm{cm}^{-1}$. The NMR spectrum consists of two broad absorptions centered at $\tau 6.6$ and $\tau$ 8.6, which are assigned respectively to the two methylene groups adjacent to oxygen (total $4 \mathrm{H}$ ) and to the remaining four methylene groups (total $8 \mathrm{H})$.

\section{Polymerization Equilibrium}

Polymerization equilibrium of cyclic ether is well exemplified by the THF polymerization. ${ }^{12,15}$<smiles>COCCCCO[C+]1CCCC1</smiles>

The monomer-polymer equilibrium in the oxepane polymerization was examined. The results are shown in Table III. By using $\mathrm{Et}_{3} \mathrm{OSbCl}_{6}$ as the initiator, oxepane was polymerized in $\mathrm{CH}_{2} \mathrm{Cl}_{2}$ for 38 days, and the monomer concentration at the final stage was determined by GLPC analysis. On the other hand, purified polymer was treated with the same initiator in $\mathrm{CH}_{2} \mathrm{Cl}_{2}$ for 18 days. The amount of monomer produced from linear polymer was also determined by GLPC. The two values of the final monomer concentrations derived from polymerization and depolymerization experiments agreed within experimental error. 
Table III. Equilibrium monomer concentration ${ }^{a}$

\begin{tabular}{|c|c|c|c|c|}
\hline \multirow{2}{*}{ At $30^{\circ} \mathrm{C}$} & \multirow[t]{2}{*}{$\begin{array}{c}\text { Time, } \\
\text { day }\end{array}$} & \multirow[t]{2}{*}{$\begin{array}{l}\text { Monomer } / \\
\text { Polymer } \\
\text { (at equili- } \\
\text { brium }\end{array}$} & \multicolumn{2}{|c|}{$\begin{array}{c}\text { Equili- } \\
\text { brium } \\
\text { monomer } \\
\text { concn, } \\
{[\mathrm{M}]_{\mathrm{e}} \times 10^{2},} \\
\mathrm{~mol} / \mathrm{l}\end{array}$} \\
\hline & & & & \\
\hline From monomer ${ }^{\mathrm{c}}$ & 38 & $2.7 / 97.3$ & & 9.3 \\
\hline \multirow[t]{2}{*}{ From polymer } & 18 & $2.4 / 97.6$ & & 7.0 \\
\hline & & & av & 8 \\
\hline \multicolumn{5}{|l|}{ At $10^{\circ} \mathrm{C}$} \\
\hline From monomer ${ }^{c}$ & 38 & $2.1 / 97.9$ & & 7.2 \\
\hline \multirow[t]{2}{*}{ From polymer ${ }^{\mathrm{d}}$} & 18 & $1.6 / 98.4$ & & 4.9 \\
\hline & & & av & 6 \\
\hline
\end{tabular}

a Polymerization and depolymerization were carried out with $\mathrm{Et}_{3} \mathrm{OSbCl}$ ( $\left.2 \mathrm{~mol} \%\right)$ in $\mathrm{CH}_{2} \mathrm{Cl}_{2}$.

b The monomer concentration in the system was determined with GLPC analysis by using 1,1,2,2-tetrachloroethane as internal standard.

c Oxepane, $8.62 \mathrm{mmol}$; $[\mathrm{M}]_{0}, 3.45 \mathrm{~mol} / l$.

d The initial concentration of the monomeric units in polymer was $2.87 \mathrm{~mol} / l$.

Thus, the average value was taken as the equilibrium monomer concentration $[\mathrm{M}]_{\mathrm{e}} ; 8 \times 10^{-2}$ $\mathrm{mol} / l$ at $30^{\circ} \mathrm{C}$ and $6 \times 10^{-2} \mathrm{~mol} / l$ at $10^{\circ} \mathrm{C}$.

The $[\mathrm{M}]_{\mathrm{e}}$ is related to the equilibrium constant $K$ and to the free energy change of the monomer-to-polymer conversion, $\Delta F^{0}$.

$$
\begin{gathered}
\mathrm{P}_{n}{ }^{*}+\mathrm{M} \stackrel{K}{\rightleftarrows} \mathrm{P}_{n+1}^{*} \\
K=\frac{\left[\mathrm{P}_{n+1}\right]^{*}}{\left[\mathrm{P}_{n}^{*}\right][\mathrm{M}]_{\mathrm{e}}}=\frac{1}{[\mathrm{M}]_{\mathrm{e}}} \\
\therefore \quad \Delta F^{\prime}=-R T \ln K=R T \ln [\mathrm{M}]_{\mathrm{e}}
\end{gathered}
$$

It has been reported that the polymerization of oxetane (four-membered cyclic ether) is not reversible. ${ }^{16}$ On the other hand, the THF polymerization is reversible and the conversion percent at equilibrium in bulk polymerization is not very high, e.g., it is $83 \%\left([\mathrm{M}]_{\mathrm{e}}=2.1 \mathrm{~mol} / l\right)$ at $10^{\circ} \mathrm{C}$ and $73 \%\left([\mathrm{M}]_{\mathrm{e}}=3.4 \mathrm{~mol} / \mathrm{l}\right)$ at $30^{\circ} \mathrm{C}$. The free energy decrease of the oxepane polymerization is intermediate between the corresponding values of the polymerizations of oxetane and THF. This finding qualitatively agrees with the results of the thermochemical estimation of free energy change of the cyclic ether polymerizations based upon the hypothetical

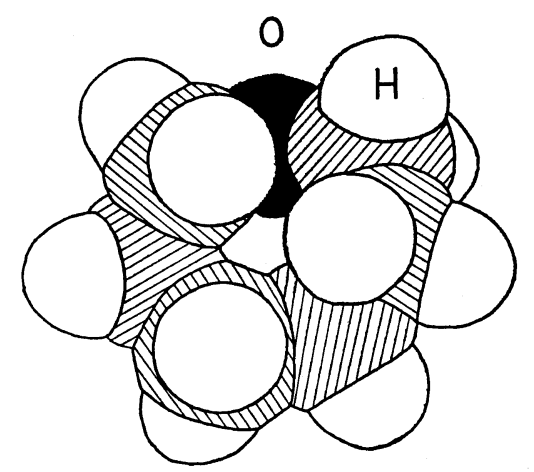

Figure 1. A molecular model for oxepane.

polymerizations of cycloparaffins. ${ }^{17}$

The free energy decrease of the polymerization of cyclic compounds is ascribed mainly to the strain energy of monomer. ${ }^{17}$ Thus the strain of oxepane is higher than that of THF. As depicted in the molecular model of Figure 1, the strain of oxepane may be attributed to the transannular repulsion between the pseudo-axial hydrogen atoms. ${ }^{18}$ The kinetic study of the oxepane polymerization is now in progress, which will be published elsewhere.

\section{EXPERIMENTAL}

\section{Reagents}

THF and $\mathrm{CH}_{2} \mathrm{Cl}_{2}$ were commercial reagents and purified as described previously. ${ }^{3,19}$ Oxetane was prepared according to $\operatorname{Ros}^{16}$ and rectified over $\mathrm{KOH}$ and metallic sodium, successively. $\mathrm{BF}_{3} \mathrm{THF}$ complex was prepared by passing $\mathrm{BF}_{3}$ gas into $\mathrm{THF}$ at $0^{\circ} \mathrm{C}$ and was purified by distillation under reduced nitrogen pressure, bp $69^{\circ} \mathrm{C}$ $(4 \mathrm{~mm}){ }^{3} \quad \mathrm{Et}_{3} \mathrm{OBF}_{4}$ was prepared by the method of Meerwein, et al., ${ }^{20}$ and purified by reprecipitation $\left(\mathrm{CH}_{2} \mathrm{Cl}_{2}\right.$-ether) and dried in vacuo at room temperature. $\mathrm{Et}_{3} \mathrm{OSbCl}_{6}$ was prepared similarly, ${ }^{20}$ recrystallized from 1,2-dichloroethane-ether system, and dried in vacuo. $\mathrm{AlEt}_{3}-\mathrm{H}_{2} \mathrm{O}(1: 0.5)$ system was prepared as described before. ${ }^{19}$

Other reagents were purified by ordinary procedures.

\section{Preparation of Oxepane}

6-Bromo-1-hexanol 1. Commercial reagent of hexamethylene glycol was treated with hydrobromic acid at $80^{\circ} \mathrm{C}$ under continuous extraction of the reaction product with petroleum ligroin. 
The extract was washed successively with aq alkali solution and water, subjected to evaporation of ligroin at $50-60^{\circ} \mathrm{C}$ under reduced pressure, and finally distilled at reduced nitrogen pressure to give a $36-\%$ yield of 1, bp $85^{\circ} \mathrm{C}$ $(0.7 \mathrm{~mm}){ }^{21}$

Oxepane. Oxepane monomer was prepared by the reaction of $\mathrm{KOH}^{11}$ on 1 at $140^{\circ} \mathrm{C}$ in tetralin. The reaction product was continuously distilled out at $150 \mathrm{mmHg}$ and purified by repeated fractional distillations over sodium metal after the treatment with bromine water. The purity of the product oxepane was over $99.9 \%$ by GLPC analysis (yield 12\%): bp $120.5^{\circ} \mathrm{C}, d_{4}^{18} 0.862$; NMR $\left(\mathrm{CDCl}_{3}\right) \tau 6.3\left(\mathrm{~m}, 4 \mathrm{H}, \mathrm{CH}_{2} \mathrm{OCH}_{2}\right)$ and $8.3 \mathrm{ppm}\left(\mathrm{m}, 8 \mathrm{H}, \mathrm{CH}_{2}-\left(-\mathrm{CH}_{2}-\right)_{2}-\mathrm{CH}_{2}\right)$.

\section{Polymerization}

Polymerization was carried out in $\mathrm{CH}_{2} \mathrm{Cl}_{2}$ solution under nitrogen atmosphere. The reaction was initiated by the addition of a catalyst solution to $1 \mathrm{~m} l(8.62 \mathrm{mmol})$ of monomer. After a desired time of reaction, the polymerization system was terminated by the addition of excess methanol.

\section{REFERENCES}

1. T. Saegusa, Y. Hashimoto, and S. Matsumoto, Macromolecules, 4, 1 (1971).

2. T. Saegusa and S. Matsumoto, J. Polym. Sci., Part A-1, 6, 1559 (1968).

3. T. Saegusa and S. Matsumoto, Macromolecules, 1, 442 (1968).
4. T. Saegusa, S. Matsumoto, and Y. Hashimoto, Polymer J., 1, 31 (1970).

5. T. Saegusa and S. Matsumoto, J. Macromol. Sci., A4, 873 (1970).

6. BASF, Neth. Appl. 6514413 (1966).

7. A. Franke, et al., Monatsh, 69, 167 (1936).

8. BASF, Ger. Patent 840844 (1952).

9. N. S. Andreev, Otdel. Khim. Nauk, 373 (1961).

10. N. Hamaide, Bull. Soc. Chim. France, 789 (1957).

11. G. Gailer, Methoden der Organischen Chemie, 4/5, 450 (1966).

12. H. Meerwein, D. Delfs, and H. Morshel, Angew. Chem., 72, 927 (1960).

13. E. B. Ludvig, B. A. Rozenberg, T. M. Zvereva, A. R. Gantmakher, and S. S. Medvedev, Vysokomol. Soedin, 7, 269 (1965).

14. T. Saegusa, S. Matsumoto, and T. Ueshima, Makromol. Chem., 105, 132 (1967).

15. M. P. Dreyfuss and P. Dreyfuss, J. Polym. Sci., Part A-1, 4, 2179 (1966).

16. J. B. Rose, J. Chem. Soc., 542 (1956).

17. F.S. Dainton, T. R.E. Devlin, and P. A. Small, Trans. Faraday Soc., 51, 1710 (1955).

18. Ya. I. Gol'dfarb and L. I. Belen'kii, Russ. Chem. Revs., 29, 214 (1960).

19. H. Imai, T. Saegusa, S. Matsumoto, T. Tadasa, and J. Furukawa, Makromol. Chem., 102, 222 (1967).

20. H. Meerwein, E. Battenberg, H. Gold, E. Pfeil, and G. Willfang, J. Prakt. Chem., 154, 83 (1939).

21. E. F. Degering and L. G. Boatright, J. Amer. Chem. Soc., 72, 5137 (1950). 